\title{
Past land-cover change for climate modeling: data from Eastern Asia
}

\author{
Xianyong Cao', U. Herzschuh', M.-J. Gaillard² ${ }^{1}$ K. Morrison ${ }^{3}$ and Q. Xu \\ Shijiazhuang, China, 6-11 March 2017
}

This workshop and related training course were held at Hebei Normal University in Shijiazhuang, China, and organized within the activities of PAGES' working group LandCover6k. The major aim was to gather the coordinators of the LandCover6k working sub-group Asia-Oceania, experts in the field of quantitative pollen-based vegetation reconstruction, and data contributors (pollen, archaeology, history) The purpose was to (i) explain and discuss the objectives and research strategies of LandCover6k, (ii) assess the availability of fossil pollen records and pollen data archives/databases, pollen productivity estimates (parameters needed for pollenbased quantitative estimates of plant cover), and archaeological and historical data, and (iii) plan the future activities necessary to achieve the objectives of LandCover6k in Asia-Oceania. Following a win-win collaborative approach during the workshop, an intensive training course was held on the methodological tools for pollen-vegetation modeling and calculation of pollen productivity estimates. The course also included instruction on upscaling of archaeological data to a global scale landuse scheme. Anthropogenic land-coverchange modeling was provided to the data contributors to facilitate the achievement of the LandCover6k objectives, and data contributors were encouraged to use those methodological tools for their own scientific questions. The workshop was attended by 83 participants including 63 Chinese and Indian young scientists and students.

The four major outcomes of the workshop are:

(i) An evaluation of spatial pollen-based reconstructions of vegetation cover and climate, and discussion on their interpretation and reliability issue.

(ii) Discussion on the status and availability of databases for pollen records in Eastern Asia. In particular, X Cao and U Herzschuh presented an extension of Eastern continental Asia pollen dataset (Cao et al. 2013; 2014) to Siberia (Fig. 1), and Jian Ni presented the development of a new version of the Chinese Quaternary Pollen Database.

(iii) The launch of the State Key Program of National Natural Science Foundation of China "Quantitative pollen-based

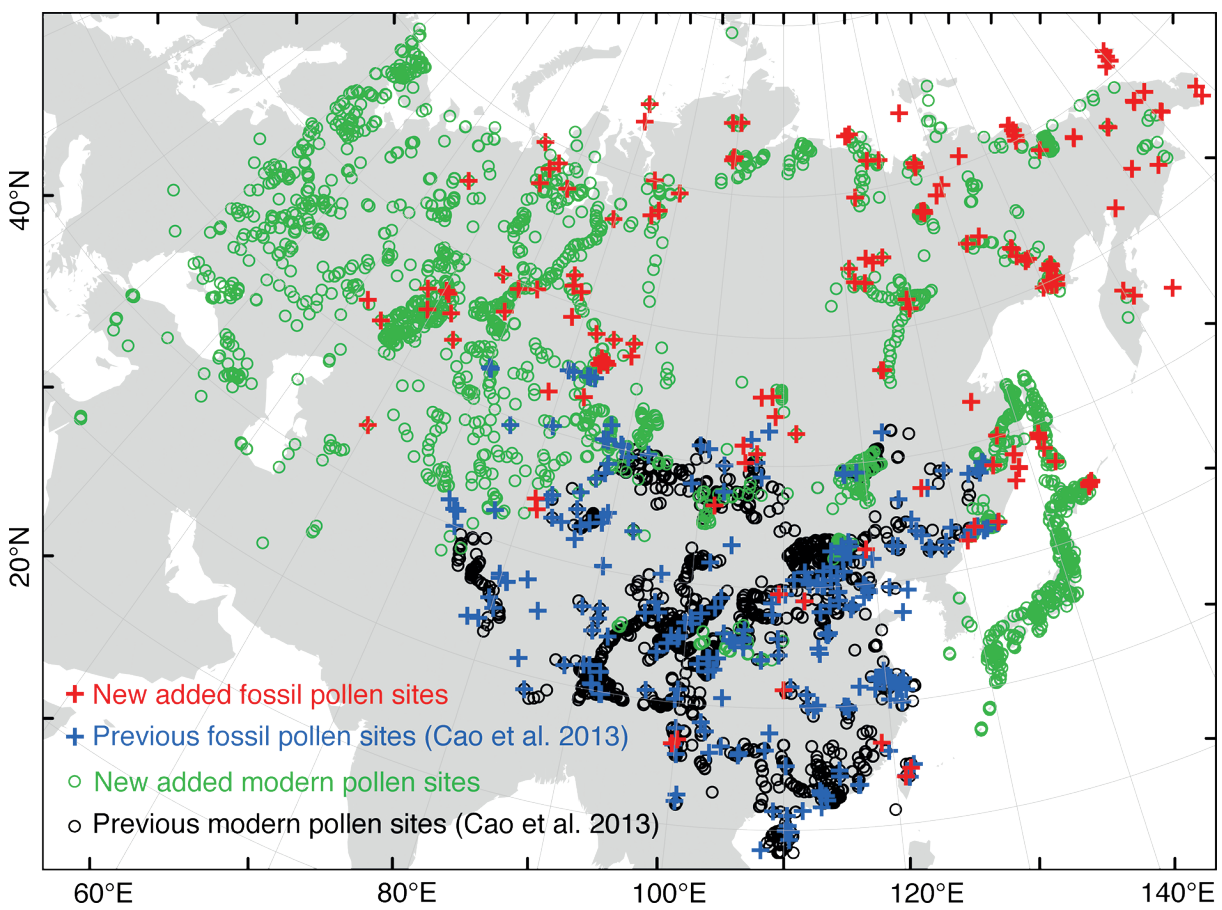

land-cover reconstruction $\left(1^{\circ} \times 1^{\circ}\right)$ for the purpose of climate modeling in China since $6 \mathrm{ka}$ " coordinated by $\mathrm{Q} X \mathrm{X}$, which includes studies of pollen productivity estimates in all major vegetation and climate zones of China and pollen-based reconstructions of past vegetation cover using REVEALS model (Sugita 2007).

(iv) Teaching and dissemination of methods, tools and strategies for pollen-data handling (e.g. the R program and packages for statistical computing), pollen-based climate and vegetation reconstructions (e.g. weighted averaging partial least squares WA-PLS, modern analogue technique MAT), calculation of pollen productivity estimates (ERV model), pollen-based reconstruction of vegetation cover (REVEALS and LOVE models), and land-use inference from historical and archaeological data.

By regularly following up on the four outcomes above, we expect that the workshop will result in a higher number of scientists in Eastern Asia who will (i) contribute new pollen productivity estimates for the major plant taxa characteristic for that region and (ii) submit fossil pollen records to international pollen archives and databases. This process will significantly improve the requirements for reliable reconstructions of past anthropogenic vegetation cover in Eastern Asia for the purpose of LandCover6k's goals.

\section{AFFILIATIONS}

'Alfred Wegener Institute Helmholtz Centre for Polar and Marine Research, Research Unit Potsdam, Germany

2Department of Biology and Environmental Science, Linnaeus University, Kalmar, Sweden

${ }^{3}$ Department of Anthropology, University of Pennsylvania and Museum of Archaeology and Anthropology, Philadelphia, USA ${ }^{4}$ College of Resources and Environment Sciences, Hebei Normal University, Shijiazhuang, China

\section{CONTACT}

Xianyong Cao: Xianyong.Cao@awi.de

REFERENCES

Cao Xet al. (2013) Rev Palaeobot Palynol 194: 21-37 Cao X et al. (2014) Rev Palaeobot Palynol 211: 87-96 Sugita S (2007) Holocene 17: 229-241

Figure 1: Extension of the Eastern continental Asia pollen dataset to North Asia, with 199 newly added fossil pollen records and 3943 modern pollen data. In total, the dataset now includes 470 fossil and 6569 modern pollen data. 